Document downloaded from:

http://hdl.handle.net/10251/82101

This paper must be cited as:

Benajes Calvo, JV.; García Martínez, A.; Monsalve Serrano, J.; Balloul, I.; Pradel, G. (2016). An assessment of the dual-mode reactivity controlled compression ignition/conventional diesel combustion capabilities in a EURO VI medium-duty diesel engine fueled with an intermediate ethanol-gasoline blend and biodiesel. Energy Conversion and Management. 123:381-391. doi:10.1016/j.enconman.2016.06.059.

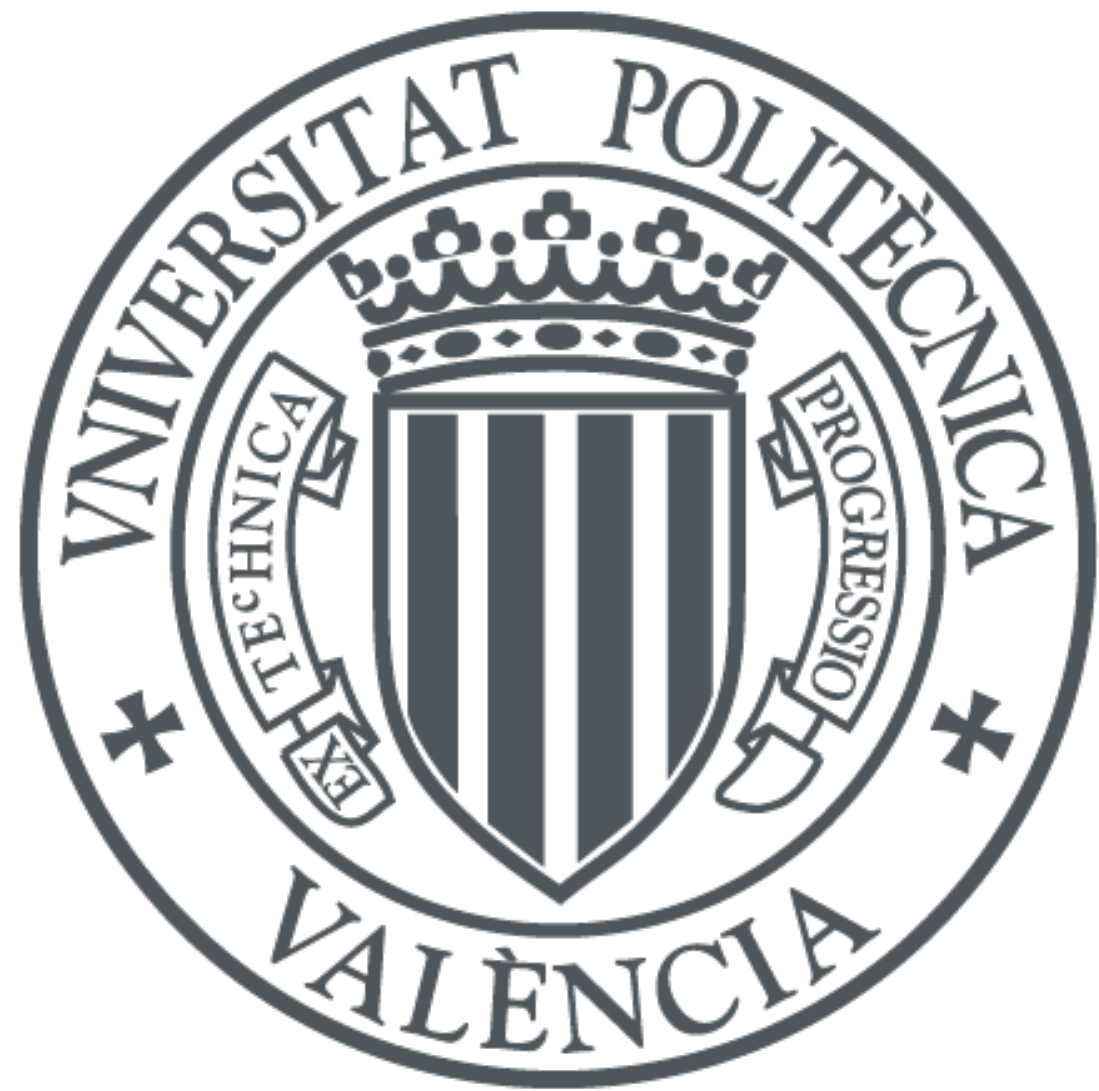

The final publication is available at

http://doi.org/10.1016/j.enconman.2016.06.059

Copyright Elsevier

Additional Information 


\title{
An assessment of the dual-mode Reactivity Controlled Compression Ignition/Conventional Diesel Combustion capabilities in a EURO VI medium-duty diesel engine fueled with an intermediate ethanol-gasoline blend and biodiesel
}

Energy Conversion and Management, Volume 123, 1 September 2016, Pages 381-391. http://dx.doi.org/10.1016/j.enconman.2016.06.059

\author{
Jesús Benajes ${ }^{1}$, Antonio García ${ }^{1,{ }^{*}}$, Javier Monsalve-Serrano ${ }^{1}$, Iyad Balloul ${ }^{2}$ and Gérard \\ Pradel $^{2}$ \\ ${ }^{1} \mathrm{CMT}$ - Motores Térmicos, Universitat Politècnica de València, Camino de Vera $\mathrm{s} / \mathrm{n}$, \\ 46022 Valencia, Spain \\ ${ }^{2}$ VOLVO Group Trucks Technology, 99 Route de Lyon, 69806 Saint Priest, France
}

Corresponding author $(*)$ :

Dr. Antonio Garcia (angarma8@mot.upv.es)

Phone: +34 963879659

Fax: +34 963877659

\section{Abstract}

This work investigates the capabilities of the dual-mode reactivity controlled compression ignition/conventional diesel combustion engine operation to cover the full operating range of a EURO VI medium-duty diesel engine with compression ratio of 17.5:1. This concept is based on covering all the engine map switching between the reactivity controlled compression ignition and the conventional diesel combustion operating modes. Specifically, the benefits of reactivity controlled compression ignition combustion are exploited whenever possible according to certain restrictions, while the conventional diesel combustion operation is used to cover the zones of the engine map in which the reactivity controlled compression ignition operation is limited.

The experiments were conducted using a single-cylinder research diesel engine derived from the multi-cylinder production engine. In addition, considering the mandatory presence of biofuels in the future context of road transport and the ability of ethanol to be blended with gasoline, the low reactivity fuel used in the study is a blend of $20 \%$ ethanol by volume with $80 \%$ of 95 octane number gasoline. Moreover, a diesel containing $7 \%$ of biodiesel has been used as high reactivity fuel. Firstly, a reactivity controlled compression ignition mapping is performed to check the operational limits of the concept in this engine platform. Later, based on the results, the potential of the dual-mode concept is discussed.

Results suggest that, under the constraints imposed, reactivity controlled compression ignition combustion can be utilized between $25 \%$ and $35 \%$ load. In this region of the map, reactivity controlled compression ignition can provide up to $2 \%$ increased gross indicated efficiency than conventional diesel combustion, but led to lower efficiency at low engine speeds. In addition, it was demonstrated that the regeneration periods of the diesel particulate filter during dual-mode operation can be reduced more than 
twice, which entails a great reduction of the diesel fuel amount injected in the exhaust line.

\section{Keywords}

Reactivity controlled compression ignition; Dual-fuel combustion; Dual-mode operation; EURO VI emissions; Biofuels

\section{Introduction}

As response of the regulations introduced around the world to limit the pollutant emissions associated to internal combustion engines, researchers and manufacturers are focusing their efforts on developing new combustion strategies and aftertreatment technologies to fulfill the stringent limitations imposed. Since the complex aftertreatment devices incur additional costs and fuel consumption, the emissions reduction from the in-cylinder standpoint is clearly necessary.

The more promising combustion strategies to improve the efficiency of compression ignition engines while reducing their most harmful emissions, nitrogen oxides (NOx) and soot, are the low temperature combustion (LTC) strategies. In this sense, many researchers have shown that LTC strategies such as homogeneous charge compression ignition ( $\mathrm{HCCl}$ ) and partially premixed combustion (PPC) are capable of inhibiting the emission of these two pollutants while maintaining high thermal efficiency. To do so, $\mathrm{HCCl}$ combustion relies on achieving a homogeneous fuel-air mixture in the cylinder prior to be ignited due to the high pressure and temperatures experienced during compression stroke [1]. However, since combustion control can be only done by managing the charge conditions at intake valve close (IVC), the concept becomes highly dependent on engine operating conditions, restricting $\mathrm{HCCl}$ operation to the partial load range. The PPC strategy allows increasing the feasible operating range by promoting certain degree of fuel stratification in the chamber. This stratification promotes a staged combustion event with reduced pressure-rise rates (PRR) than $\mathrm{HCCl}$ operation, thus increasing the load limits [2]. However, great challenges regarding combustion control and mechanical engine stress were still identified due to the great auto-ignition qualities of diesel fuel [3].

To overcome this drawback, the use of gasoline-like fuels was widely investigated as method for improving the combustion control of LTC modes. Kalghatgi al. [4] introduced the concept of gasoline partially premixed combustion (PPC) in 2006. They demonstrated that the use of a fuel with higher resistance to autoignition than diesel allows extending the ignition delay without the need of high EGR fractions, too early injection timings, too low compression ratios or unconventional hardware. Moreover, this work evidenced that the larger mixing time provides a well-mixed charge prior to combustion, which leads to lower NOx and soot emissions as compared to diesel operation. These findings confirmed gasoline PPC as promising method to improve the heat release control while providing a simultaneous reduction in NOx and soot emissions. However, the concept demonstrated difficulties at low load conditions using gasoline with octane number (ON) greater than 90 [5]. At these conditions, the spark assistance provided temporal [6] and spatial control over the gasoline PPC combustion process [7], but resulted in unacceptable NOx and soot emissions [8], even using double injection strategies [9]. Thus, experiments performed by Bessonette et al. 
[10] suggested that, to achieve proper operation, the fuel characteristics must vary depending on the engine operating conditions. Specifically, diesel-like fuels are required at low load and fuels with gasoline-like autoignition qualities are required at high load.

Inagaki et al. [11] proposed a dual-fuel combustion concept combining the port fuel injection of iso-octane and direct injection of diesel fuel. They found that this type of combustion provides very low NOx and soot emissions and great control of the combustion process. In particular, the spatial stratification of ignitability was managed by changing the ratio of both fuels over the total amount injected. More recently, Kokjohn et al. [12] reinforced these promising results by means of computational studies and re-baptized this combustion concept as reactivity controlled compression ignition ( $\mathrm{RCCl})[13]$.

Many researchers have demonstrated that $\mathrm{RCCl}$ is a more promising LTC technique than $\mathrm{HCCl}$ and PPC. The work performed by Splitter et al. [14], in which $\mathrm{HCCl}$ and $\mathrm{RCCl}$ were compared at matched conditions, proved that $\mathrm{RCCl}$ technique enables smoothing the heat release rate, leading to lower PRR and combustion noise than $\mathrm{HCCl}$. Moreover, significant differences in combustion losses and heat transfer were seen, both having a direct effect on net efficiency. In addition, the use of high EGR rates [15], together with the gasoline fraction and direct injection timing variation during $\mathrm{RCCl}$ operation [16], allow an effective control of the in-cylinder equivalence ratio and reactivity stratification [17] to promote the conditions necessary to achieve ultra-low NOx and soot emissions [18] together with better fuel consumption than conventional diesel combustion (CDC) in a wide operating range of the engine [19].

In spite of the benefits obtained with $\mathrm{RCCl}$ concept, it was found that unburned hydrocarbons ( $\mathrm{HC}$ ) and carbon monoxide (CO) emissions levels are considerably higher than CDC, mainly at low load operation. At these operating conditions, combustion efficiency values around $97 \%$ were observed. In this sense, it was demonstrated that these results can be improved up to values above $98 \%$ by combining the effects of incylinder gas temperature and oxygen concentration respectively with the in-cylinder fuel blending ratio [20]. Moreover, it was also confirmed that certain levels of unburned $\mathrm{HC}$ and $\mathrm{CO}$ remained unaffected in spite of the engine settings modification. This behavior was previously identified to be consequence of the gasoline trapped in the crevice and squish volumes, which represents the primary source of incomplete combustion in RCCl combustion [20]. In addition, it was confirmed that RCCl concept also offers an interesting potential for improving fuel consumption by lowering wall heat transfer. Thus, with the aim of minimizing the unburned products and improve the indicated efficiency of the concept, the influence of piston geometry on RCCI combustion was also studied in literature [21]. In this case, it was found that a bathtub style piston with low surface area allowed a $2 \%$ to $4 \%$ absolute increase in gross indicated efficiency, which was attributed to both combustion efficiency and heat transfer improvement [22]. Some other geometries aimed at reducing the heat transfer losses were also tested [23], confirming that the best strategy to increase the efficiency of $\mathrm{RCCl}$ concept is by reducing the in-cylinder area-to-volume ratio [24]. However, these studies showed that an excessive shallow bowl combined with single injection strategies can result in unacceptable soot emissions when trying to extend the $\mathrm{RCCl}$ concept up to high loads [25]. 
A previous work of the authors demonstrated that, if ultra-low NOx and soot emissions are pretended to be reached by only operating under $\mathrm{RCCl}$ regime, the maximum operable load becomes restricted due to the excessive pressure rise rates (PRR) experienced [26]. In particular, $\mathrm{RCCl}$ operation was limited to $50 \%$ load in the case of using a CR of $14.4: 1$ and was limited to $70 \%$ when using a CR of 11:1. Thus, the present research focuses on evaluating the capabilities of the dual-mode $\mathrm{RCCl} / \mathrm{CDC}$ operation to cover the full engine map. In this sense, despite the dual-mode strategy will not allow avoiding the use of SCR and DPF aftertreatment systems needed for CDC operation, the higher thermal efficiency of $\mathrm{RCCl}$ versus $C D C$ may yield to global fuel savings depending on the drive cycle considered. Moreover, the dual-mode implementation will relieve the aftertreatment systems requirements, which has direct repercussions on their durability and the exhaust fluids costs. To perform the study, a currently available biodiesel fuel (B7) and a near-term intermediate ethanol-gasoline blend (E20-95) were used, which confers an interesting perspective to the work considering the key role that biofuels will play in road transport [27].

\section{Experimental facilities and processing tools}

This section describes the main characteristics of the test cell used in this study, focusing on the engine unit and the different systems of which is equipped. Moreover, the main properties of the fuels used in the present investigation are detailed here.

Finally, some considerations about the methodology followed during the experimental tests and the bases of the theoretical tool used to process the data acquired from the engine, are provided.

\subsection{Test cell and engine description}

The experiments presented in this work were conducted using a single-cylinder diesel engine derived from a EURO VI multi-cylinder production engine representative of urban freight distribution fleet. The main specifications of the engine are depicted in Table 1, and their power and IMEP curves are shown in Figure 1.

Table 1. Main specifications of the medium-duty engine used in this study.

\begin{tabular}{|l|c|}
\hline Style & 4 Stroke, DI diesel engine \\
\hline Manufacturer / model & VOLVO / D5K240 \\
\hline OEM ECU calibration & EURO VI \\
\hline Piston bowl geometry & Re-entrant \\
\hline Maximum power & $177 \mathrm{~kW} @ 2200 \mathrm{rpm}$ \\
\hline Maximum in-cylinder pressure & $190 \mathrm{bar}$ \\
\hline Bore x Stroke & $110 \mathrm{~mm} \times 135 \mathrm{~mm}$ \\
\hline Connecting rod length & $212.5 \mathrm{~mm}$ \\
\hline Crank length & $67.5 \mathrm{~mm}$ \\
\hline Total displaced volume & $5100 \mathrm{~cm}^{3}$ \\
\hline Number of cylinders & 4 \\
\hline Compression ratio & $17.5: 1$ \\
\hline
\end{tabular}




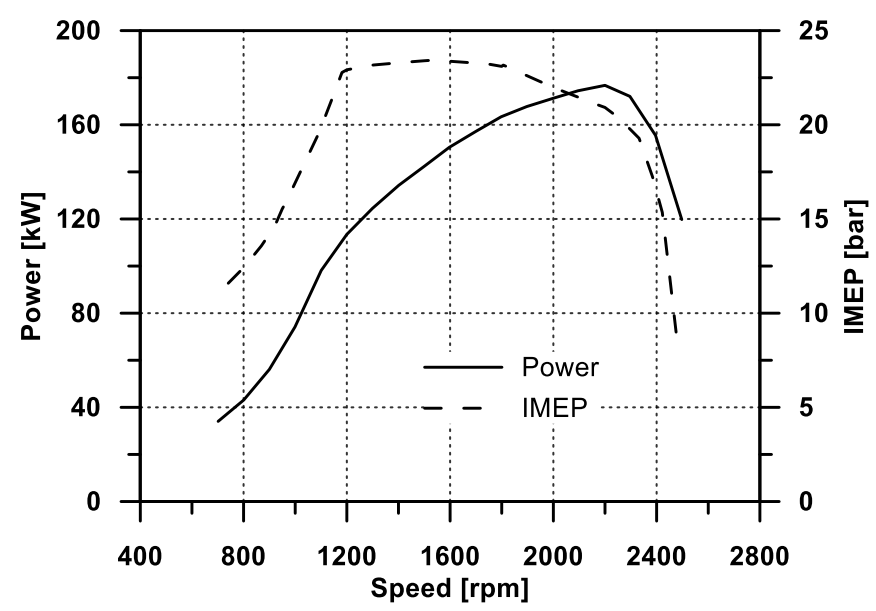

Figure 1. Power and IMEP curves of the engine VOLVO D5K240 used in this study.

To fulfill the limits imposed by the EURO VI regulation, the VOLVO D5K240 engine relies on the injection of additional fluids into the exhaust line for improving the efficiency of the aftertreatment systems. First, a water-cooled air-assisted injector delivers certain amount of diesel fuel at 4 bar upwards the DOC for heat management purposes. In addition, the increase of the exhaust gas temperature is also intended to ensure a good efficiency of the DPF and SCR functionality. Later, with the aim of improving the SCR catalytic efficiency, urea fluid is injected upwards the SCR using an air-assisted dosing system. To do so, a control module calculates the urea dosing rate needed based on various engine parameters, and the exact quantity of urea is mixed with air from the vehicle compressed air system. Then, a single-hole injector nozzle injects the urea-air mixture in the center of the exhaust stream. The layout of the different aftertreatment systems in the exhaust line and the location of the two injectors is illustrated in Figure 2 [28].

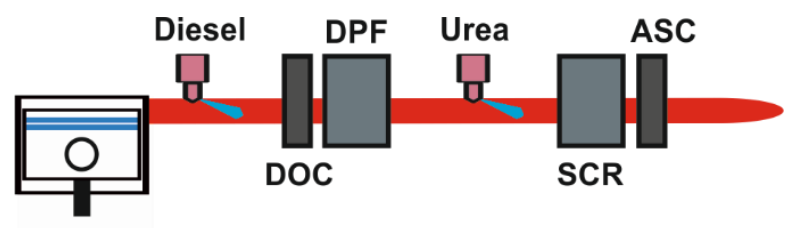

Figure 2. Scheme of the exhaust line of the engine VOLVO D5K240 used in this study. Two additional injections of fluid (diesel and urea) are used to improve the efficiency of the aftertreatment systems.

The engine was installed in a fully instrumented test cell, with all the auxiliary facilities required for its operation and control, as it is illustrated in Figure 3. A particularity of the test cell set-up is that the engine used is not a conventional SCE research engine, but is a hybrid solution between a MCE and SCE. This engine configuration allows to study an isolated cylinder as conventional SCE engine, while the three remaining cylinders are governed using the OEM ECU to balance the cylinder-to-cylinder maximum pressure and load. Similar test cell configurations are found in $[29,30]$. This approach results in a much cheaper solution than the conventional SCEs used for research purposes, also allowing switching to the MCE version to broaden the 
spectrum of the study. However, as the crankshaft and the dynamometer are shared between both engine sides, it is not possible to obtain isolated torque-based parameters during the hybrid operation, which force to study the combustion process using indicated parameters. As expected, when switching to the MCE version, this limitation disappears.

As can be seen in Figure 3, the MCE side is also fully instrumented, which allows monitoring each subsystem during the engine operation. Thus, the in-cylinder pressure signals from both sides (SCE and MCE) are monitored in real-time for balancing purposes. In this sense, as the SCE conditions varied during the RCCI studies, the MCE settings were modified to provide similar maximum pressure, engine load and combustion phasing. Finally, it is interesting to note that as the MCE side of the engine is not used for studying the combustion process, the EGR rate was annulled to compensate part of the gas lost due to the isolated cylinder.

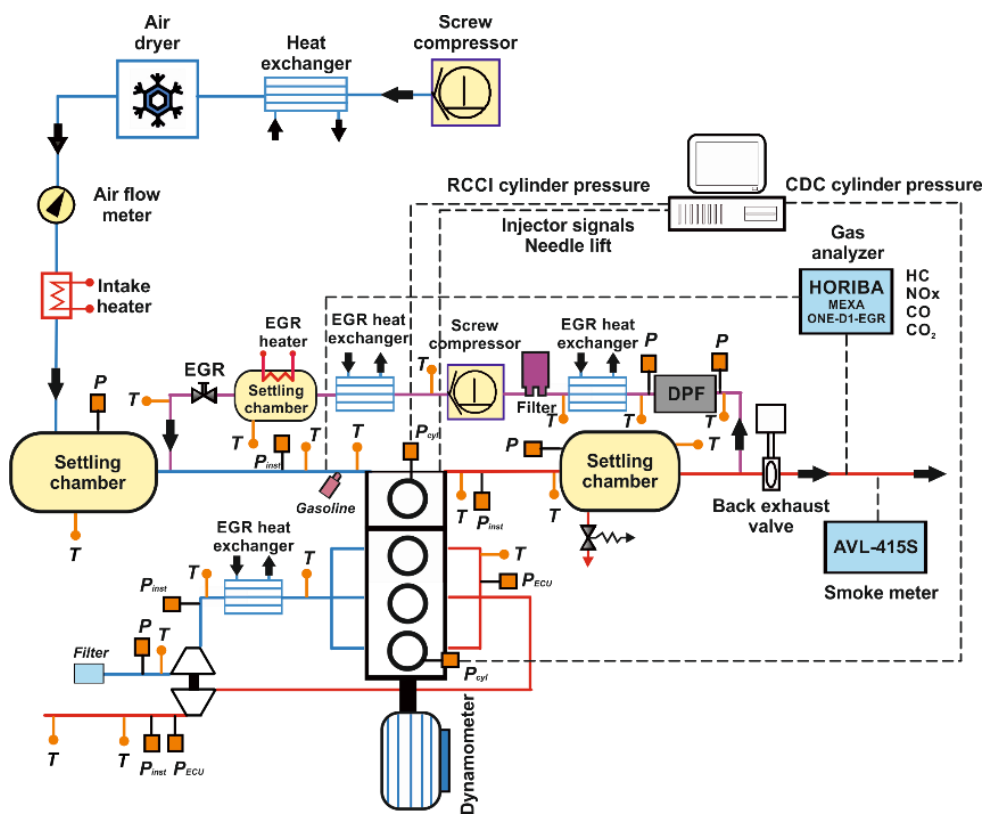

Figure 3. Test cell scheme showing the hybrid configuration. One cylinder is fully isolated and controlled by a full-pas Drivven controller. For balancing purposes, the three remaining cylinders operate under CDC conditions governed by the OEM ECU settings.

From the test cell scheme shown in Figure 3, it can be seen that the main modifications done for isolating the cylinder in which the combustion study will be performed (from now on, SCE) are regarding air management. In particular, to achieve stable intake air conditions, a screw compressor supplied the required boost pressure before passing through an air dryer. The air pressure was adjusted within the intake settling chamber, while the intake temperature was controlled in the intake manifold after mixing with the EGR flow. The exhaust backpressure produced by the turbine in the real engine was replicated by means of a valve placed in the exhaust system, controlling the pressure in the exhaust settling chamber. Low pressure EGR was produced taking exhaust gases from the exhaust settling chamber. The determination of the EGR rate was carried out using the experimental measurement of intake and exhaust carbon dioxide $\left(\mathrm{CO}_{2}\right)$ concentration. The concentrations of $\mathrm{NOx}, \mathrm{CO}$, unburned $\mathrm{HC}$, intake and exhaust $\mathrm{CO}_{2}$, and oxygen $\left(\mathrm{O}_{2}\right)$ were analyzed with a five gas Horiba MEXA-ONE-D1-EGR analyzer bench by averaging 40 seconds after attaining steady state operation. $\mathrm{CO}$ and 
unburned $\mathrm{HC}$ measurements were used to determine the combustion efficiency as shown in Equation 1 [31]:

$$
\text { Comb. Eff }=\left(1-\frac{\mathrm{HC}}{\mathrm{mf}}-\frac{\mathrm{CO}}{4 \cdot \mathrm{mf}}\right) \cdot 100
$$

Smoke emission were measured with an AVL 415S Smoke Meter and averaged between three samples of a 1 liter volume each with paper-saving mode off, providing results directly in Filter Smoke Number (FSN) units. Particulate matter measurements of FSN were transformed into specific emissions $(\mathrm{g} / \mathrm{kWh})$ by means of the factory AVL calibration. In spite of that the blow-by is supposed to be minimum in a heavy-duty engine, knowing its value allows to calculate more accurately the in-cylinder instantaneous mass, which increases considerably the precision of the theoretical models used for the combustion diagnosis. Thus, in this research, the flow of the blowby gas has been monitored by an AVL 442 blow-by meter. Finally, the in-cylinder pressure signal was measured with a Kistler $6125 \mathrm{C}$ pressure transducer coupled with a Kistler 5011B10 charge amplifier. A shaft encoder with 1800 pulses per revolution, which provides a resolution of 0.2 CAD, was used.

\subsection{Fuels and delivery}

Previous works showed the potential of biofuels for increasing the efficiency of RCCl concept. In these studies, a diesel fuel containing 7\% of biodiesel (B7) was used as high reactivity fuel [32]. Moreover, considering the mandatory presence of biofuels in the future context of road transport and the ability of ethanol to be blended with gasoline, the low reactivity fuels selected were E10-95, E10-98, E20-95 and E85 [33].

Due to its particular characteristics, such as high enthalpy of vaporization and high octane number, the E85 fuel grade was investigated by many other researchers. However, the remaining blends were not investigated in literature as LRF candidates for $\mathrm{RCCl}$ operation. The relatively low ethanol quantity used in the three intermediate ethanol-gasoline (compared to E85) and the variation in gasoline ON were intended to find the proper reactivity gradient between the high and low reactivity fuels that allowed exploiting the characteristics of ethanol while minimizing some of the drawbacks related to diesel/E85 operation (high amount of HC and CO emissions, low thermal efficiency at low load and reduced volumetric fuel economy).

The studies were performed using the nominal CR of 14.4:1 at low load and an effective CR of 11:1 at medium and high loads. In all the cases, the most suitable combination of biofuels was $\mathrm{B} 7+\mathrm{E} 10-95$ as it provided highest gross indicated efficiency with ultra-low NOx and soot low emissions. In addition, further work showed that this combination of biofuels allows achieving a clean and efficient operation up to full load when using an effective CR of 11:1, but practically the RCCI concept is limited to around $70 \%$ load due to excessive in-cylinder PRRs [26]. Taking into account this experimental background and considering the high CR of the production engine used in the current, the LRF selected for performing this study was E20-95. As depicted in Table 2 , this fuel blend contains a $19.7 \%$ of ethanol content by volume, while the rest of the fuel contained in the blend is gasoline of 95 RON. In addition, the HRF selected was diesel B7 as it showed good performance when combined with this intermediate 
ethanol-gasoline blend. The main properties of both fuels are listed in Table 2, and their distillation curves are depicted in Figure 4. All the properties were obtained following ASTM standards.

Table 2. Physical and chemical properties of the fuels used along the study.

\begin{tabular}{|l|c|c|}
\cline { 2 - 3 } \multicolumn{1}{c|}{} & Diesel B7 & E20-95 \\
\hline Density $\left[\mathrm{kg} / \mathrm{m}^{3}\right]\left(\mathrm{T}=15^{\circ} \mathrm{C}\right)$ & 837.9 & 745 \\
\hline Viscosity $\left[\mathrm{mm}^{2} / \mathrm{s}\right]\left(\mathrm{T}=40{ }^{\circ} \mathrm{C}\right)$ & 2.67 & - \\
\hline Reid vapor pressure $[\mathrm{kPa}]$ & - & 59 \\
\hline RON [-] & - & 99.1 \\
\hline MON [-] & - & 85.6 \\
\hline Biodiesel content by volume [\%] & 7 & - \\
\hline Aromatics [\%] & 25.8 & 18.2 \\
\hline Carbon/Hydrogen/Oxygen [\%] & $85.9 / 13.3 / 0.8$ & $80.4 / 13 / 6.6$ \\
\hline CxHyOz & $15.25 / 32.13 / 0.14$ & - \\
\hline sulfur content [mg/kg] & 1.4 & $<1$ \\
\hline Ethanol content by volume [\%] & - & 19.7 \\
\hline Cetane number [-] & 54 & - \\
\hline Lower heating value [kJ/kg] & 42.61 & 40.05 \\
\hline
\end{tabular}

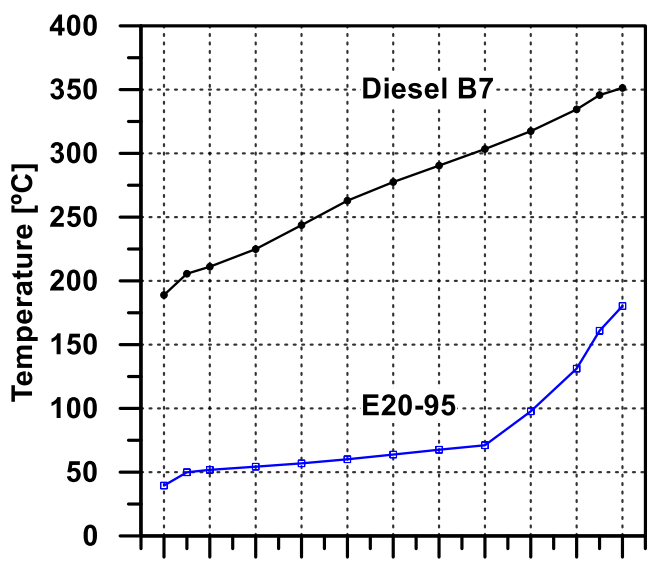

IBP 102030405060708090 FBP

Distillate volume [\%]

Figure 4. Distillation curves of biodiesel B7 and E20-95 fuel.

To enable $\mathrm{RCCl}$ operation the engine was equipped with a double injection system, as it is shown in the scheme of Figure 5 . This injection hardware enables to vary the incylinder fuel blending ratio and fuel mixture properties according to the engine operating conditions. For this purpose, the OEM ECU was replaced by a Drivven engine controller to allow full access for controlling the injection parameters of both $\mathrm{DI}$ and PFI systems. 


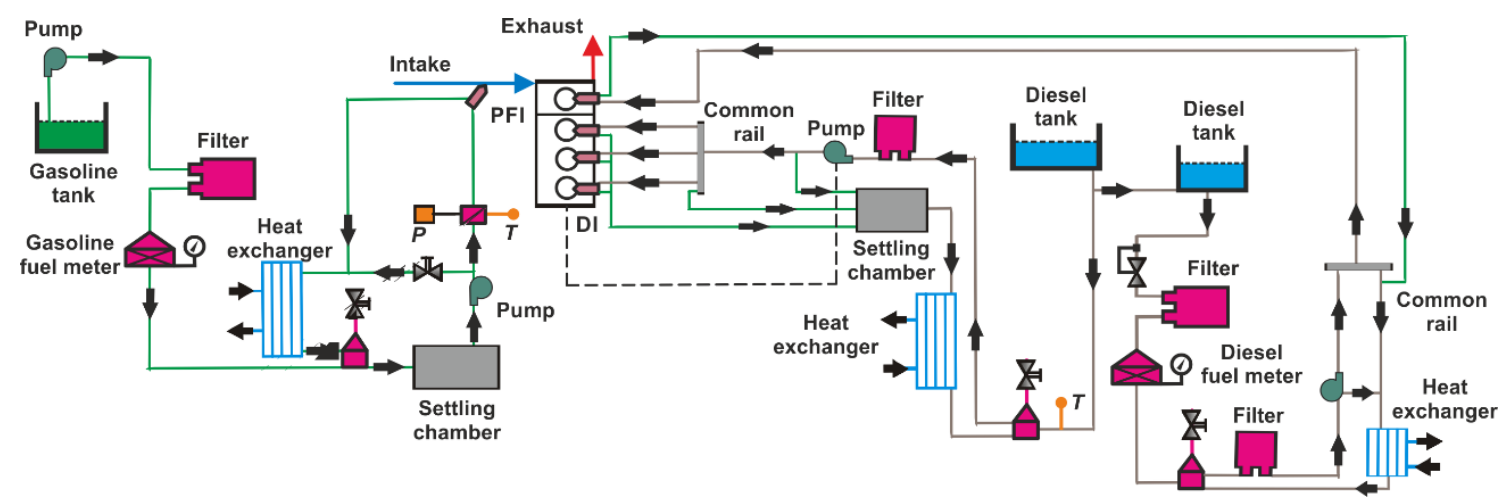

Figure 5. Fuel injection systems scheme.

To inject the diesel fuel, the engine was equipped with a common-rail injection hardware. The main characteristics of the injector and nozzle used are depicted in Table 3.

Table 3. Main characteristics of the high reactivity fuel injector.

\begin{tabular}{|l|c|}
\hline Actuation Type & Solenoid \\
\hline Steady flow rate @ $100 \mathrm{bar}\left[\mathrm{cm}^{3} / \mathrm{min}\right]$ & 1300 \\
\hline Number of Holes & 7 \\
\hline Hole diameter $[\mu \mathrm{m}]$ & 177 \\
\hline Included Spray Angle $\left[{ }^{\circ}\right]$ & 150 \\
\hline
\end{tabular}

Concerning the low reactivity fuel injection, an additional fuel circuit was in-house developed with a reservoir, fuel filter, fuel meter, electrically driven pump, heat exchanger and a commercially available port fuel injector (PFI). The mentioned injector was located at the intake manifold and was specified to be able to place all the low reactivity fuel into the cylinder during the intake stroke. Consequently, the injection timing was fixed 10 CAD after the IVO to allow the fuel to flow along the distance from the PFI location to the intake valves seats. Accordingly, this set up would avoid fuel pooling over the intake valve and the undesirable variability introduced by this phenomenon. The main characteristics of the port fuel injector are depicted in Table 4.

Table 4. Main characteristics of the low reactivity fuel injector.

\begin{tabular}{|l|c|}
\hline Injector Style & Saturated \\
\hline Steady flow rate @ 3 bar $\left[\mathrm{cm}^{3} / \mathrm{min}\right]$ & 980 \\
\hline Included Spray Angle $\left[^{\circ}\right]$ & 30 \\
\hline Injection Pressure [bar] & 5.5 \\
\hline Injection Strategy & Single \\
\hline Start of Injection Timing & 340 CAD ATDC \\
\hline
\end{tabular}

The fuel injection rate, which is used as input for the combustion diagnosis tool, was simulated using a zero-dimensional model [34]. The model was calibrated by feeding it with the experimental injection rates coming from the actual injectors used, which were measured by means of the Bosch method [35]. To perform an accurate characterization of the injectors, the dedicated batch of tests included variations of the injection pressure, energizing timing of the injector as well as the temperature and pressure of the vessel, thus simulating the operating conditions experienced during the 
engine operation. Then, based on mathematical expressions and correlations, the zero-dimensional model is capable of simulating the mass flow rate for single- and multiple-injection strategies in a wide range of operating conditions.

\subsection{In-cylinder pressure signal analysis}

The combustion analysis was performed with an in-house one-zone model named CALMEC, which is fully described in [36]. This combustion diagnosis tool uses the incylinder pressure signal and some mean variables (engine speed, coolant, oil, inlet and exhaust temperatures, air, EGR and fuel mass flow...) as its main inputs.

The pressure traces from 150 consecutive engine cycles were recorded in order to compensate the cycle-to-cycle variation during the engine operation. Thus, the individual pressure data of each engine cycle was smoothed using a Fourier series lowpass filter. Once filtered, the collected cycles were ensemble averaged to yield a representative cylinder pressure trace, which was used to perform the analysis. Then, the first law of thermodynamics was applied between IVC and EVO, considering the combustion chamber as an open system because of the blow-by and fuel injection. The ideal gas equation of state was used to calculate the mean gas temperature in the chamber. In addition, the in-cylinder pressure signal allowed obtaining the gas thermodynamic conditions in the chamber to feed the convective and radiative heat transfer models [37], as well as the filling and emptying model that provided the fluiddynamic conditions in the ports, and thus the heat transfer flows in these elements. The convective and radiative models are linked to a lumped conductance model to calculate the wall temperatures.

The main result of the model is the rate of heat release (RoHR), which is calculated as stated in Equation 2.

$\Delta F Q L=m_{c y l} \cdot \Delta u_{c y l}+\Delta Q_{W}+p \cdot \Delta V-\left(\bar{h}_{f, i n y}-u_{f, g}\right) \cdot \Delta m_{f, \text { evap }}+R_{c y l} \cdot T_{c y l} \cdot \Delta m_{b b}$

The different terms found in the equation are explained below:

- $\triangle \mathrm{FQL}$ : This term corresponds to the thermal energy released by the fuel assuming a constant heat power along the combustion event.

- $m_{c y l} \cdot \Delta u_{c y l}$ : This is the sensible internal energy variation of the gas trapped in the control volume. As detailed in Lapuerta [38] this term is calculated by means of a specific correlation for each specie. For each temporal step, these correlations are solved as a function of the mean temperature in the control volume while pondering by the mass fraction of each specie.

- $\Delta Q_{W}$ : This terms accounts the heat transfer from the gas trapped in the control volume to the surrounding surfaces of the piston, liner, cylinder-head and valves. The model do not consider the possibility of fuel impinged in the wall. The instantaneous heat transfer coefficient between the gas and the different surfaces is based on Woschni [39] with some improvements detailed in Payri et al. [40]. For the calculation of the different wall temperatures a nodal heat transfer model was implemented [41].

- $p \cdot \Delta V$ : This term represents the total work made by the gas trapped in the control volume during the calculation period. For the instantaneous calculation of the combustion chamber volume, a mechanical deformations model is 
considered. This submodel takes into account both the pressure made by the gas on the piston head and the inertial forces generated by the alternative movement of the masses.

- $\left(\bar{h}_{f, \text { iny }}-u_{f, g}\right) \cdot \Delta m_{f, \text { evap }}$ : This term includes all the energetic considerations associated to the fuel injection process, i.e. the flow work, the heat needed to reach the evaporation temperature and the heating-up of the vapor fuel until reaching the combustion chamber temperature.

- $R_{c y l} \cdot T_{c y l} \cdot \Delta m_{b b}$ : Finally, the energy lost due to the blow-by through the piston rings is also considered. The blow-by mass is calculated using an isentropic nozzle model to simulate the gas evolution from the combustion chamber to the oil sump.

\subsection{Experimental procedure considerations}

To explore the RCCl operating limits with a well-defined criteria, an experimental procedure derived from the one described in [26] was applied. This procedure is summarized in Figure 6, where it is possible to see the constrained values used for considering an acceptable RCCl operation: NOx=0.4 g/kWh, soot $=0.01 \mathrm{~g} / \mathrm{kWh}$, maximum PRR=15 bar/CAD and $P_{\max }=190$ bar.

Looking at the Figure 6, three main steps can be identified. The first step of the general procedure is aimed at finding potential engine settings to allow stable $\mathrm{RCCl}$ operation at the desired engine load. In the second step, a loop to reach the EURO VI limits in terms of NOx and soot emissions is proposed. Finally, the third step entails a rough optimization to minimize the $\mathrm{HC}$ and $\mathrm{CO}$ emissions and improve the fuel consumption while maintaining NOx and soot emissions under the EURO VI regulation limits. 


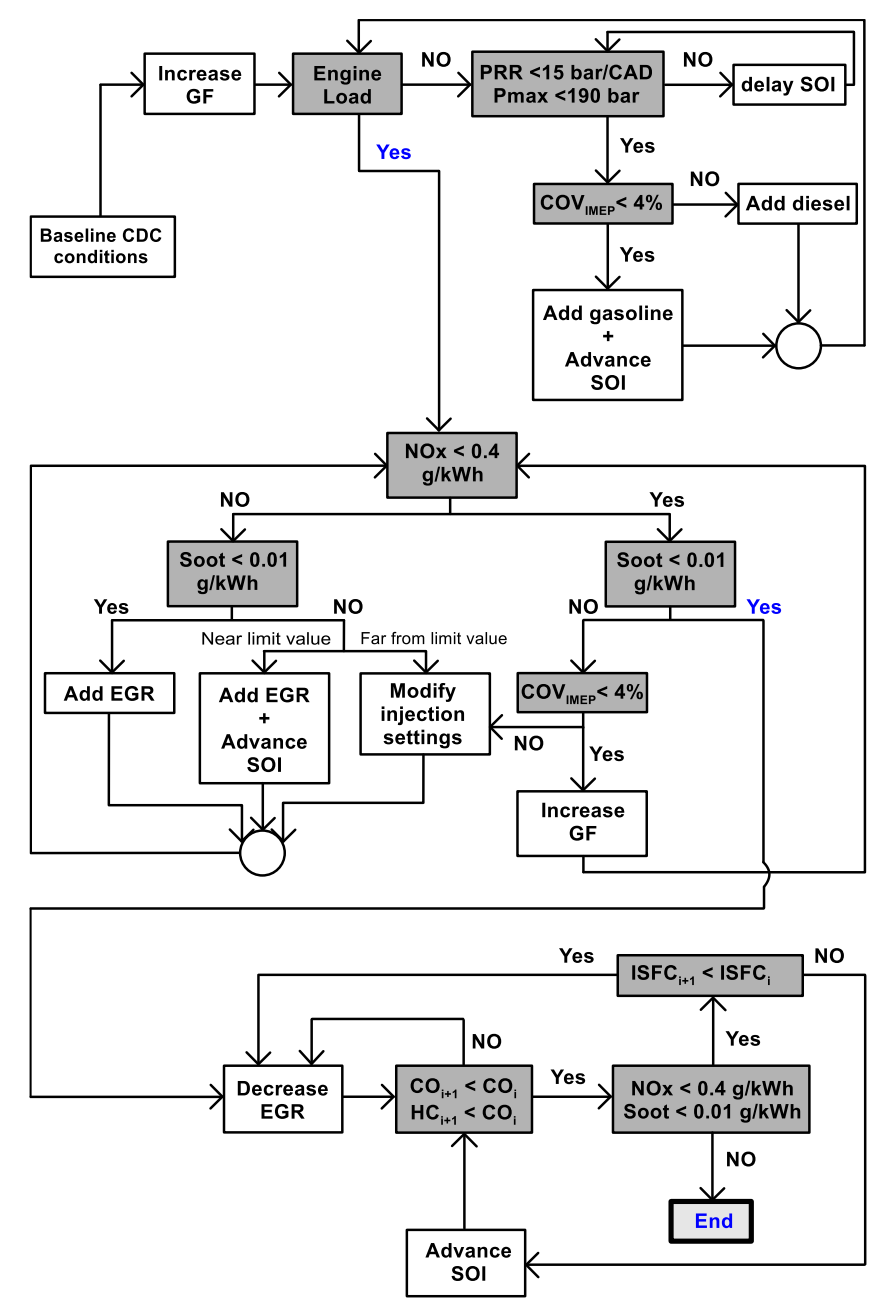

Figure 6. Experimental procedure carried out to perform the RCCI mapping.

On the other hand, to perform the discussion presented in Section 3.2 about the soot emissions reduction capabilities of the dual-mode operation, a stationary cycle similar to the world harmonized stationary cycle (WHSC) proposed by the EURO VI regulation has been considered. Figure 7 shows the different load-speed tests proposed in the WHSC, where the size of the symbols determines the weight of each test in the cycle. In addition, the actual tests performed in the engine to obtain the CDC results are depicted in the figure. As it can be seen, the experimental tests are slightly shifted to higher engine speeds than the tests proposed by the WHSC. However, since the objective is to perform a rough estimation, it has been preferred to use the exact experimental soot measurements than extrapolate the values at the specific WHSC conditions from the engine-out emissions maps. Another difference versus the WHSC is that no operating point has been tested at $650 \mathrm{rpm}$. 


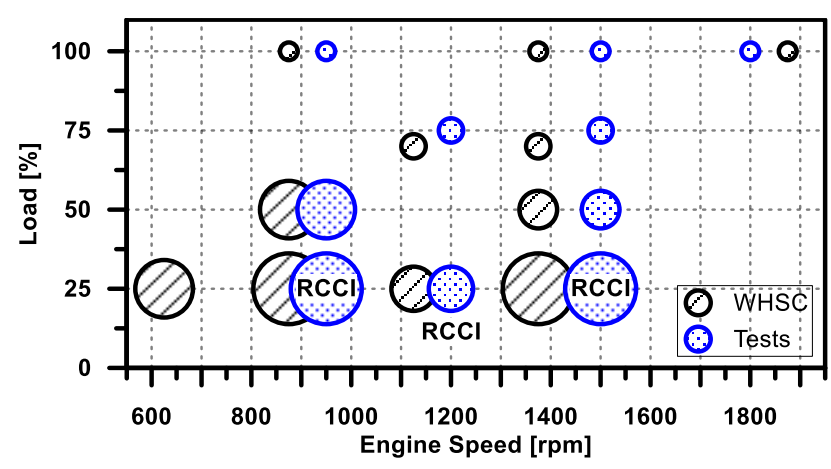

Figure 7. Tests proposed in the world harmonized stationary cycle (WHSC) and tests experimentally measured with $\mathrm{RCCl}$ and $\mathrm{CDC}$.

\section{Results and discussion}

This section contains the main results of the current investigation. The first subsection is dedicated to present the results obtained with single $\mathrm{RCCl}$ operation, which serve to stablish the operational limits of this combustion concept under the conditions studied. Later, the capabilities of the dual-mode RCCI/CDC engine operation is discussed.

\section{1. $\mathrm{RCCl}$ mapping results}

To evaluate the portion of the dual-mode map that can be covered by the $\mathrm{RCCl}$ regime using this high CR engine, an RCCl mapping was carried out. Figure 8 and Figure 9 show the results of the regulated emissions obtained after applying the experimental procedure depicted in Figure 6 . The mapping results demonstrate again the ability of $\mathrm{RCCl}$ to avoid the classical NOx-soot trade-off, providing a simultaneous reduction of both emissions up to values under the limits imposed. As expected, $\mathrm{RCCl}$ combustion results in higher $\mathrm{CO}$ and $\mathrm{HC}$ emissions than $\mathrm{CDC}$, but it is interesting to see that these levels are quite lower than those obtained in previous work using the heavy-duty engine with lower compression ratio, where the $\mathrm{CO}$ and $\mathrm{HC}$ peak levels in this load interval were around $37 \mathrm{~g} / \mathrm{kWh}$ and $23 \mathrm{~g} / \mathrm{kWh}$, respectively [26]. 

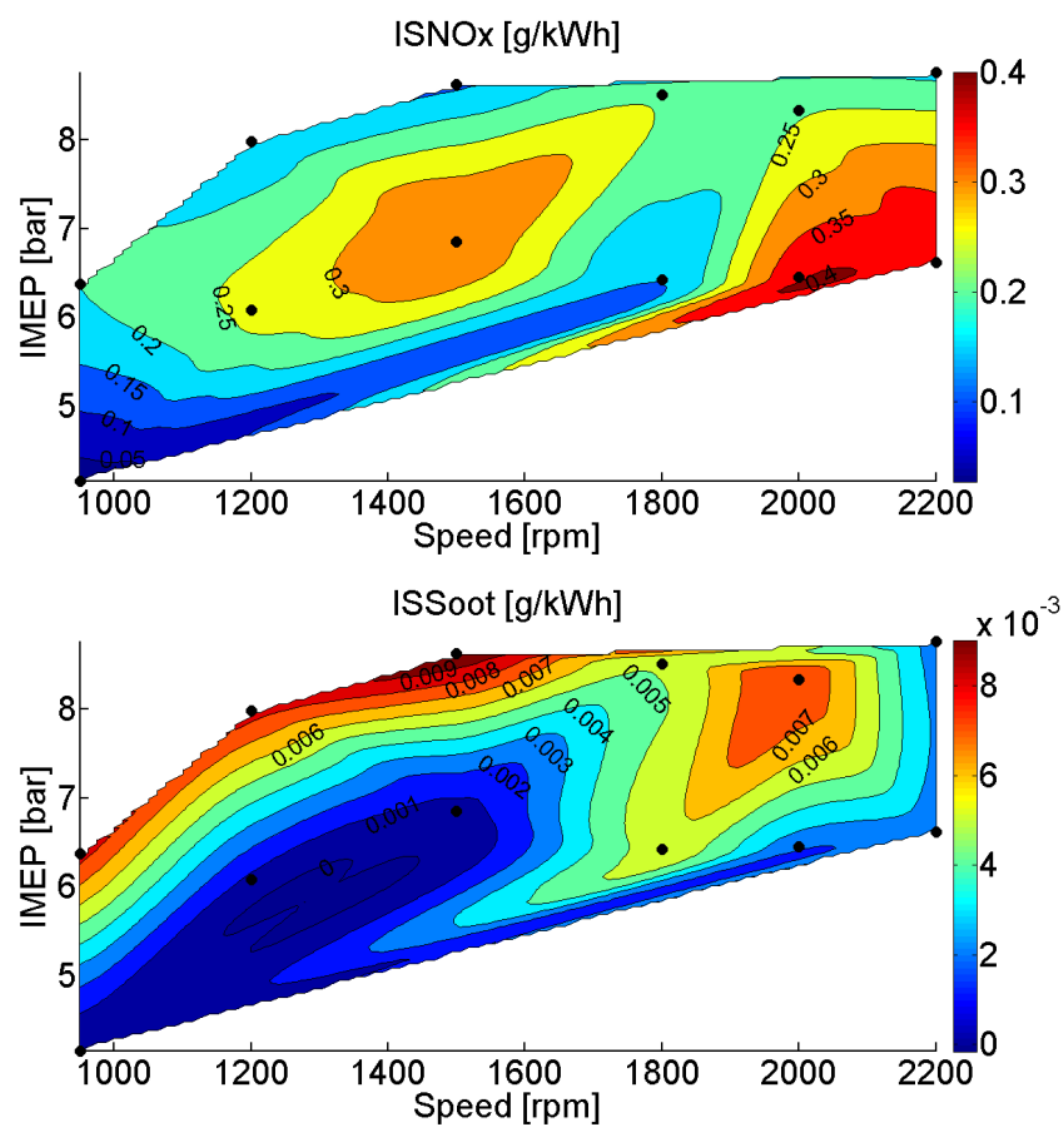

Figure 8. NOx and soot emissions mapping of $\mathrm{RCCl}$ operation on the high $\mathrm{CR}$ ratio EURO VI engine.
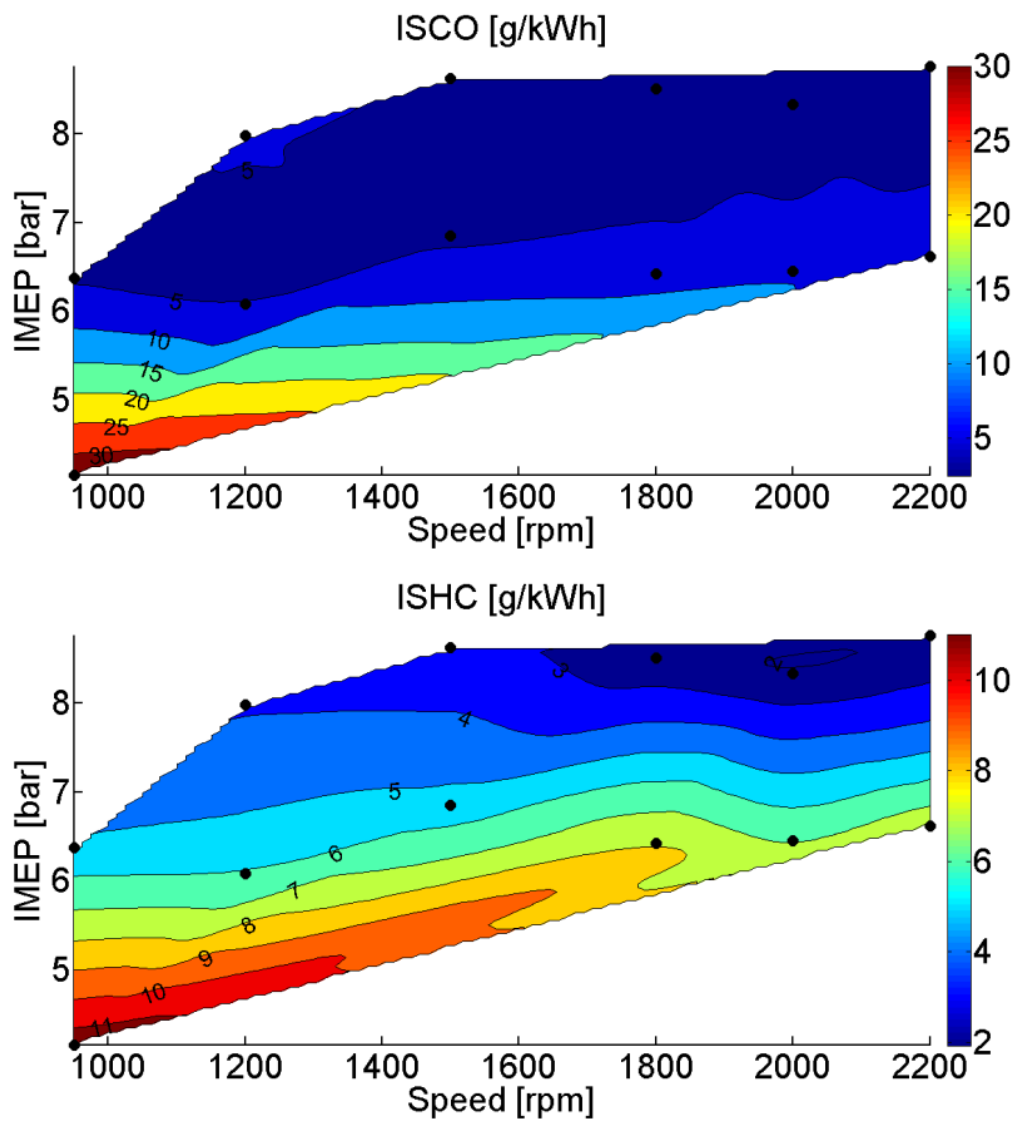

Figure 9. $\mathrm{CO}$ and $\mathrm{HC}$ emissions mapping of $\mathrm{RCCl}$ operation on the high $\mathrm{CR}$ ratio EURO VI engine. 
In spite of offering low engine-out emissions, the maximum PRR and $\mathrm{P}_{\max }$ constraints restrict the maximum operable load of $\mathrm{RCCl}$ concept to $35 \%$ at all engine speeds (Figure 10).
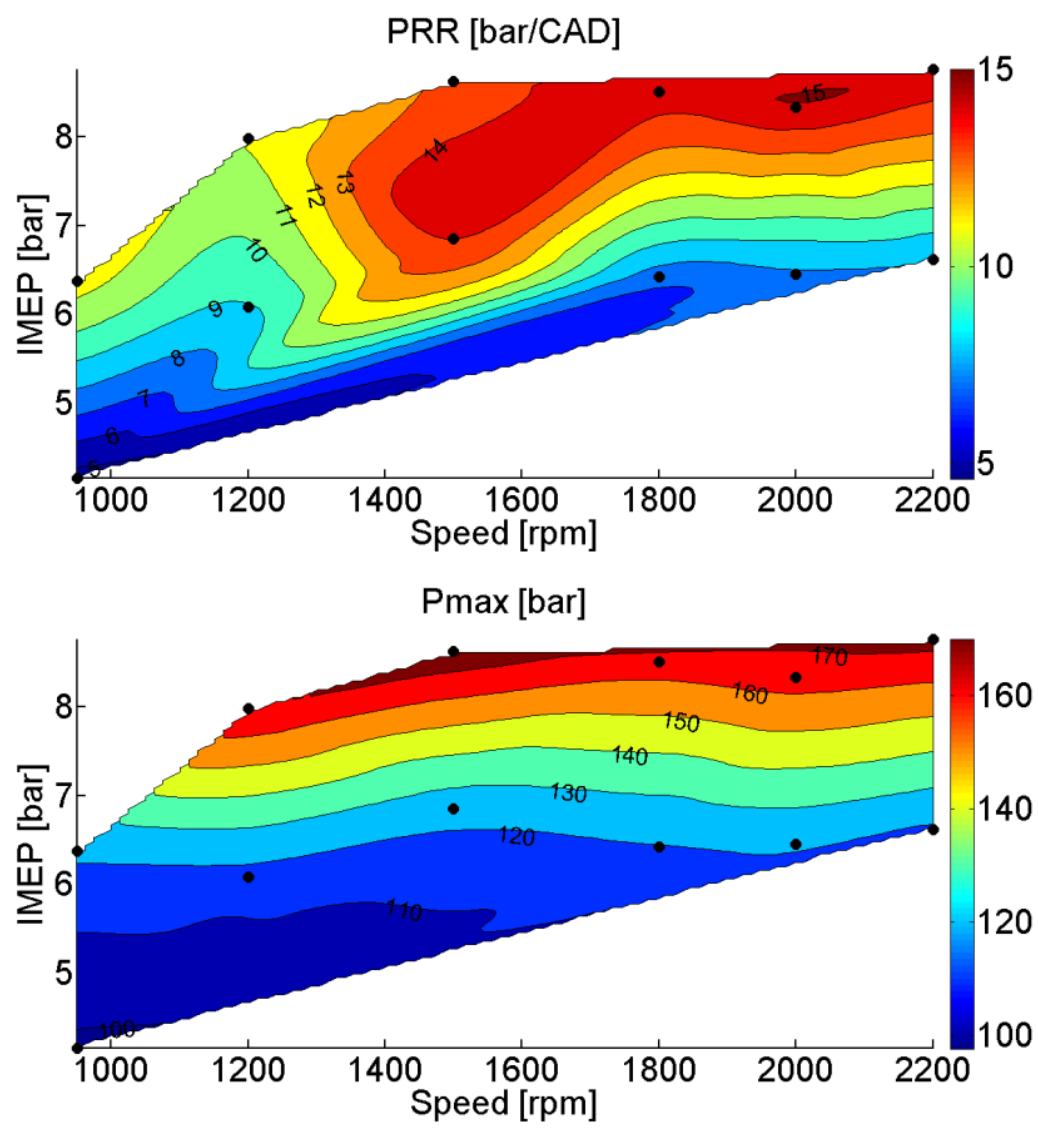

Figure 10. Maximum PRR and in-cylinder pressure levels experienced during RCCl operation in the high compression ratio EURO VI engine.

The results obtained in previous work [26] revealed several technological challenges that could arise when trying to implement the $\mathrm{RCCl}$ concept in a real engine application. One technological limitation was found to be related to the high boosting requirements needed to extend $\mathrm{RCCl}$ regime up to full load conditions. As it is shown in Figure 11, the boost pressure levels and EGR rates used to promote $\mathrm{RCCl}$ conditions in the current experiments are quite similar to those used in the production engine, which showed maximum values of $30 \%$ and 3 bar, respectively. Thus, these two variables do not represent technological limitations in this case. 

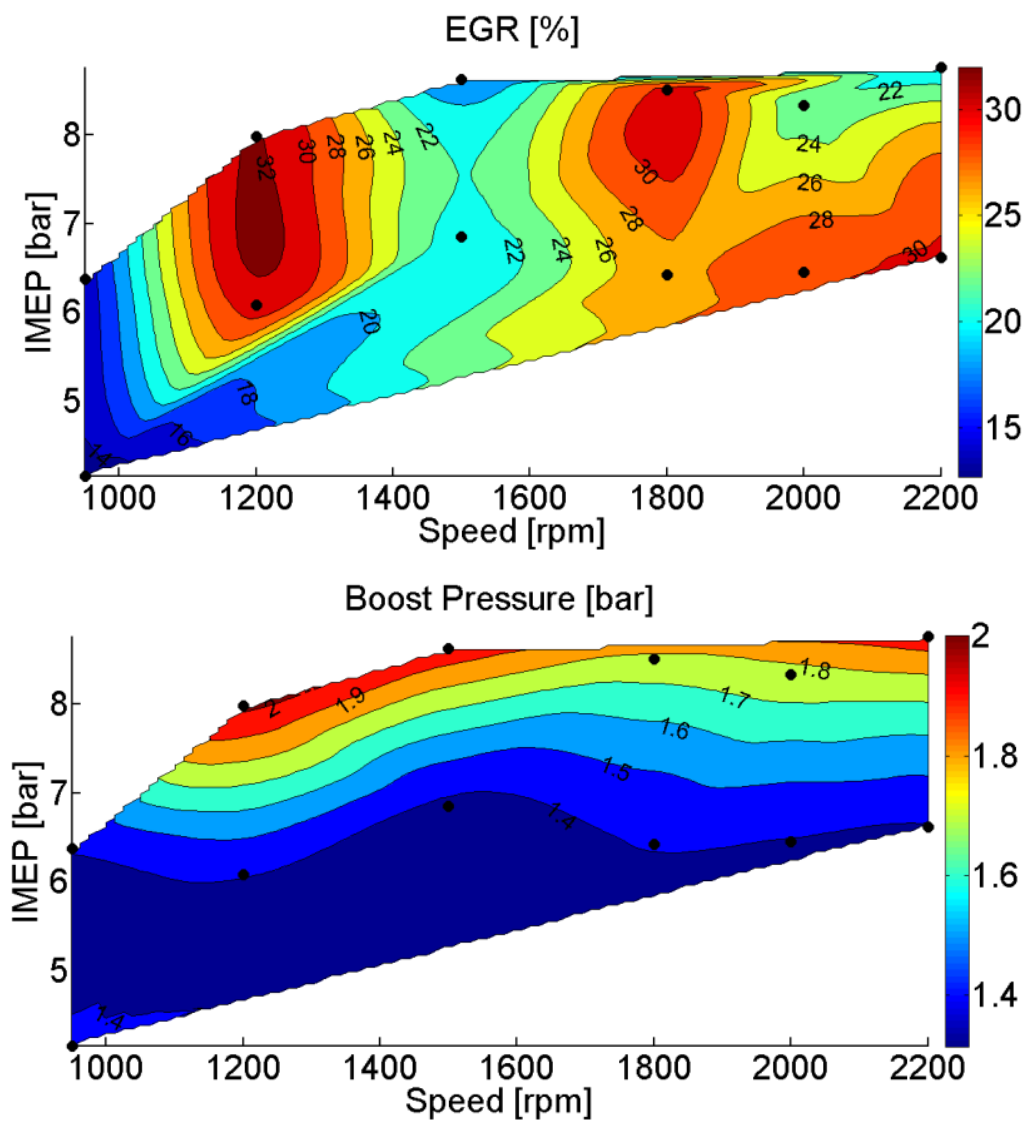

Figure 11. Boost pressure and EGR levels experienced during $\mathrm{RCCl}$ operation in the high compression ratio EURO VI engine.

Another key limitation to be considered is the low exhaust temperatures experienced during $\mathrm{RCCl}$ operation. In this sense, Prikhodko et al. demonstrated that conventional DOCs are effective in oxidizing $\mathrm{CO}$ and $\mathrm{HC}$ from $\mathrm{RCCl}$ operation at temperatures greater than $300{ }^{\circ} \mathrm{C}$, with no catalyst activity under $200{ }^{\circ} \mathrm{C}$ [42]. The results of the current work, shown in Figure 12, reveal that all the operating conditions provide exhaust temperatures above $200^{\circ} \mathrm{C}$, thus ensuring the catalytic activity during $\mathrm{RCCl}$ operation. The higher exhaust temperatures compared to those experienced in the previous work are well related with the higher compression ratio of the current engine. This fact also explains the great reduction in $\mathrm{CO}$ and $\mathrm{HC}$ emissions observed when comparing the mapping results of both engines. Moreover, it is worthy to note that the exhaust temperatures shown in Figure 12 should be even higher when the engine runs in dualmode due to the heating up of the exhaust line during CDC operation. Thus, taking into account that the exhaust temperatures are near $300^{\circ} \mathrm{C}$ in the most portion of the map, this additional heating up will ensure a great conversion efficiency of the DOC. Finally, it is possible to see that combustion noise levels of the present experiments do not exceed those obtained by other researchers [43]. 

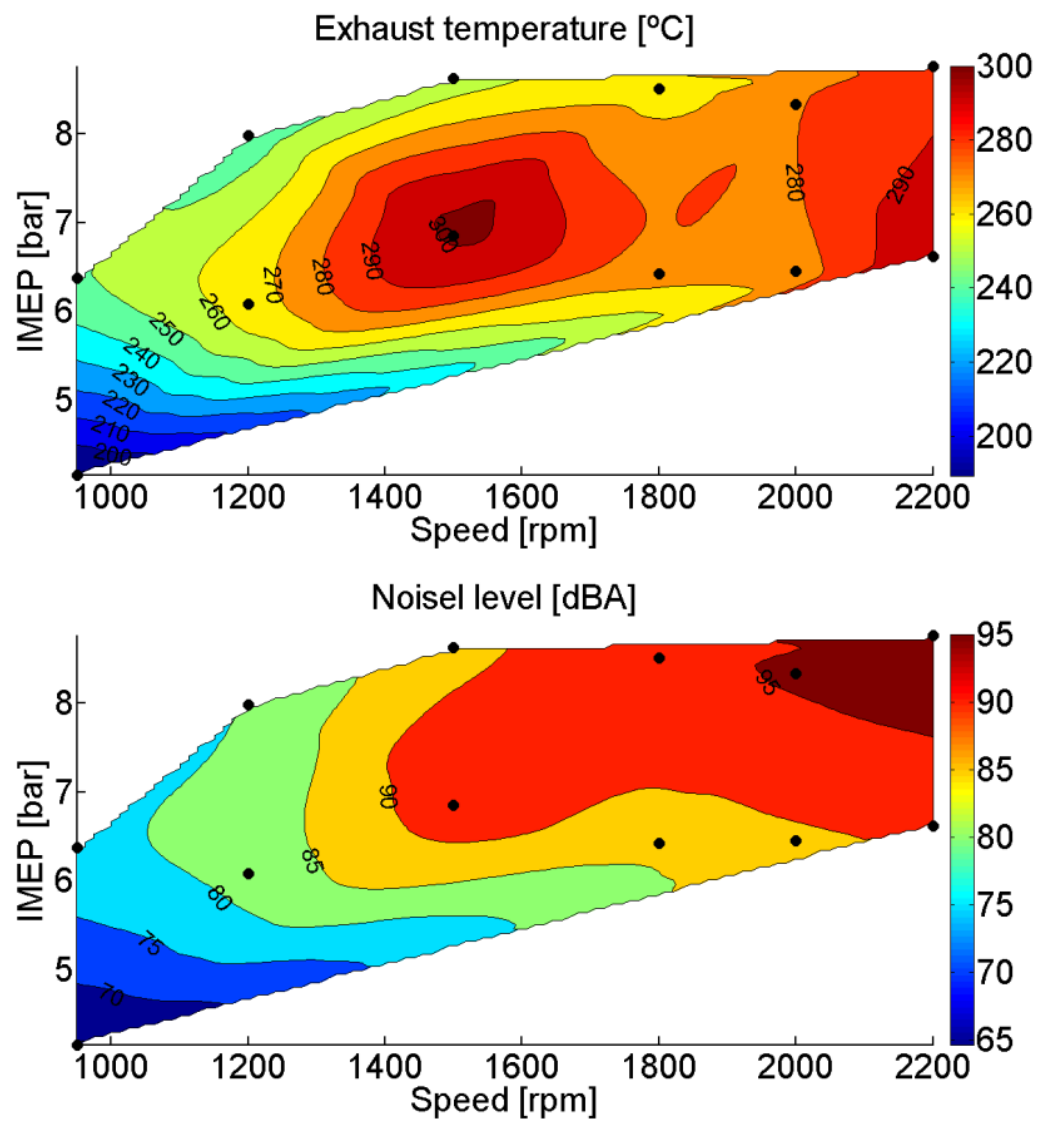

Figure 12. Exhaust temperature and combustion noise levels experienced during $\mathrm{RCCl}$ operation in the high compression ratio EURO VI engine.

Since the application of $\mathrm{RCCl}$ concept to a high compression ratio diesel engine seems to be valid to overcome the main technological challenges observed in previous works, the potential of combining $\mathrm{RCCl}$ and $\mathrm{CDC}$ concepts to cover all the engine operating range is discussed next.

\subsection{Dual-mode engine operation approach}

As it has been already remarked, the dual-mode $\mathrm{RCCl} / \mathrm{CDC}$ engine operation does not offer the possibility of removing the SCR and DPF aftertreatment systems, which questions the potential of the concept. Thus, its technological implementation only could be justified if $\mathrm{RCCl}$ provides enough increase in efficiency versus CDC to reduce considerably the fuel consumption in its operative portion of the engine map.

As described in Figure 2, two different fluids are injected into the exhaust system, which must be considered to perform a more realistic approach about the possible fuel economy advantages of the dual-mode concept. Since these two injections provide no useful work, they can be considered as an additional "fuel" consumption. Urea consumption can be estimated at $1 \%$ of the fuel consumption per $\mathrm{g} / \mathrm{kWh}$ reduction in NOx emissions [44]. Thus, the mass of urea required to reduce the engine-out NOx up to the EURO VI target can be estimated as shown in Equation 3. Since RCCl operation 
provides NOx levels under the EURO VI limit, the consumption of urea will be avoided during $\mathrm{RCCl}$ operation.

$$
m_{\text {urea }}=\left(N O x_{\text {engine-out }}-N O x_{\text {EUROVI }}\right) \cdot 0.01 \cdot m_{\text {diesel }}
$$

To account this extra "fuel" consumption, the GIE values for CDC operation can be corrected on a cost-basis as shown in Equation 4. This estimation considers the same prices for urea and diesel fuel. If the urea and diesel fuel prices were more different, the total GIE should be recalculated based on the weighted masses of urea and diesel fuel.

$$
G I E_{S C R_{-} \text {corr }}=\frac{W_{i}}{\left(m_{\text {urea }}+m_{\text {diesel }}\right) \cdot L H V}
$$

As can be seen in Figure 13, depending on the engine speed and load, this correction entails a reduction in GIE ranging from $0.5 \%$ to $4 \%$ of the $C D C$ baseline value.

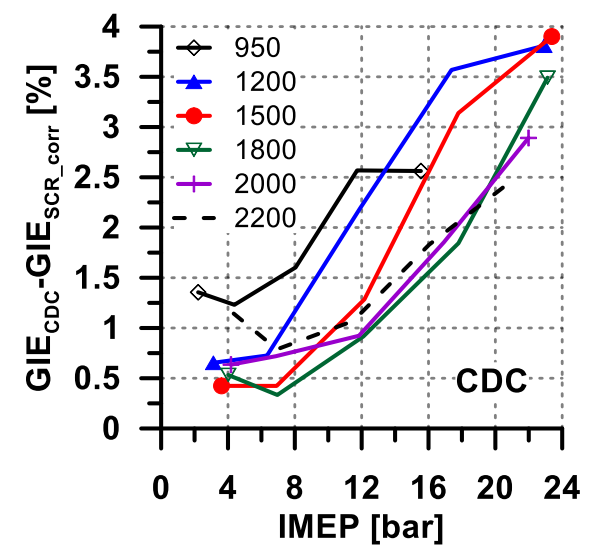

Figure 13. Reduction in GIE for CDC operation when considering the urea consumption in the calculation at different engine speeds and loads.

Considering this new scenario, the load-speed maps presented in Figure 14 show the GIE for RCCl operation and the difference between that and the corrected GIE for CDC operation. 

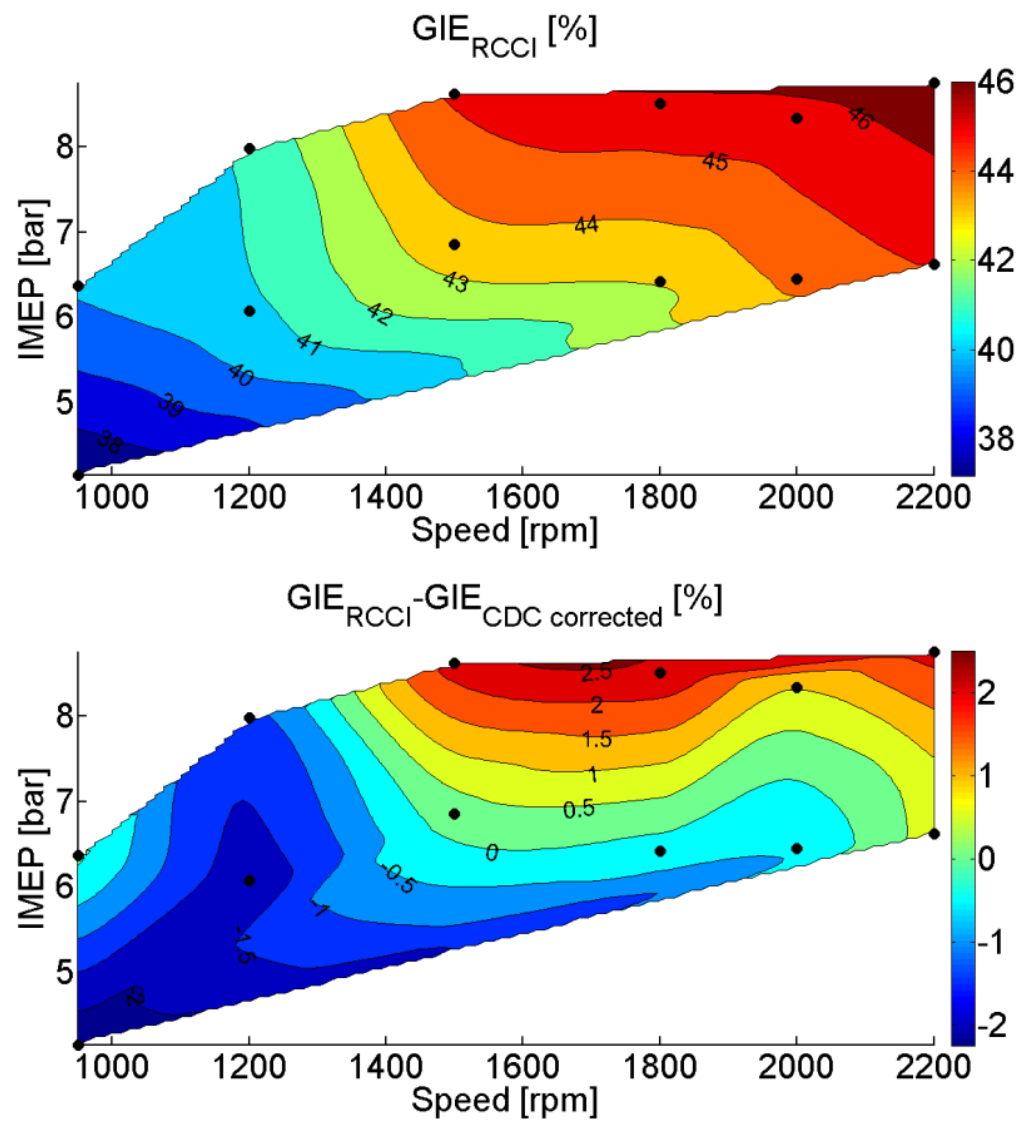

Figure 14. Mapping results of the GIE for RCCl operation and the difference between that and the corrected GIE for CDC operation.

The second subfigure shows that RCCl concept is capable of improving the GIE up to $2 \%$ in the mid-to-high speed portion of the engine map, while in the low speed land shows lower efficiency than CDC operation. Thus, the gain or loss in fuel economy provided by the dual-mode will depend on the drive cycle applied to the engine.

On the other hand, during dual-mode operation, the diesel injection ahead the DOC would be still necessary to regenerate the DPF. However, since RCCI promotes a great reduction in soot emissions versus CDC (see Figure 15), the time between regenerations during dual-mode operation could be significantly extended depending on the drive cycle applied to the engine.

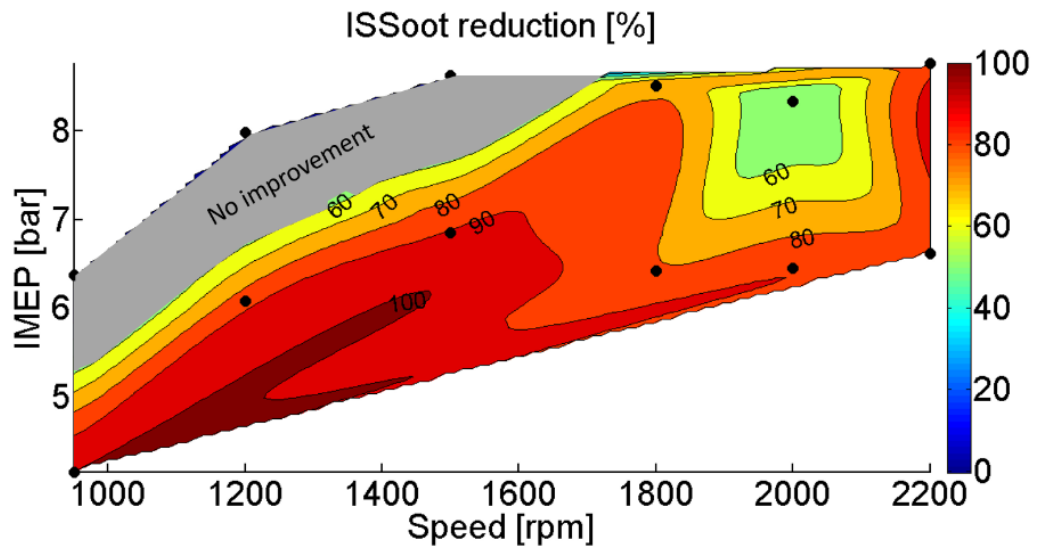

Figure 15. Reduction in soot emissions promoted by $\mathrm{RCCl}$ compared to CDC operation. 
To estimate the exhaust diesel fuel saved due to the lower demand of DPF regenerations when the engine runs in dual-mode, the total soot emissions from the stationary engine cycle described in Figure 7 have been calculated twice using the experimental measurements. Firstly, all the operating points of the cycle were tested experimentally under CDC conditions. After that, the soot emitted in a dual-mode cycle has been estimated considering that the three operating conditions at $25 \%$ load correspond to $\mathrm{RCCl}$ conditions, while the remaining points belong to $\mathrm{CDC}$ operation.

The calculation of both cycles resulted in 0.073 grams of engine-out soot for single CDC operation and 0.0308 grams for the dual-mode cycle. The great reduction in soot emissions obtained with the dual-mode strategy versus CDC (around 58\%) is explained by two reasons. The first reason is because the operating conditions at $25 \%$ load have the highest weight in the WHSC cycle. The second is that $\mathrm{RCCl}$ promotes the greatest soot reduction versus CDC at this engine load (see Figure 15). These results suggest that, practically, the regeneration periods for an engine working with dual-mode $\mathrm{RCCl} / \mathrm{CDC}$ strategy can be reduced more than twice compared to single CDC operation.

As literature demonstrates, the selection of the optimal regeneration strategy must consider the increase in BSFC due to both the backpressure increase and the extra fuel injected in the exhaust line. In this sense, the average effect of backpressure on fuel consumption will have similar magnitude during CDC or dual-mode operation, which is estimated in around $1.5 \%$ to $2.5 \%$ of BSFC [45]. On the other hand, the increase in BSFC due to the fuel amount injected in the exhaust during the regeneration periods has been estimated in around $2 \%$ to $4 \%$ [46][47]. Thus, depending on the drive cycle considered, the reduction of the regeneration periods can entail a considerable effect on total fuel consumption.

\section{Conclusions}

The present work has investigated the capabilities of the dual-mode $\mathrm{RCCl} / \mathrm{CDC}$ in a EURO VI medium-duty diesel engine derived from the serial production multi-cylinder engine. An intermediate ethanol-gasoline blend (E20-95) was used trying to exploit the high knock resistance of ethanol. In addition, diesel B7 (containing a 7\% of biodiesel) was used as high reactivity fuel.

The $\mathrm{RCCl}$ mapping results revealed that the maximum operable load to fulfill the different constraints simultaneously was $35 \%$ at all engine speeds. Moreover, it was demonstrated that the use of a high compression ratio engine allows to mitigate the technological limitations experienced in previous works developed using a lower compression ratio engine.

The evaluation of the possible benefits of the dual-mode concept in terms of fuel consumption was performed by estimating all the fluids consumed during CDC operation. Firstly, the GIE was corrected on a cost-basis to account the amount of urea necessary to reduce the NOx emissions during CDC operation. The comparison versus $\mathrm{RCCl}$ at these conditions suggested that $\mathrm{RCCl}$ can provide up to $2 \%$ increased $\mathrm{GIE}$, but led to lower efficiency at low engine speeds. Later, considering the WHSC cycle as reference, it was demonstrated that the regeneration periods of the DPF during dualmode operation can be reduced more than twice, which entails a great reduction of the diesel fuel amount injected in the exhaust line. 
These estimates hint that the dual-mode has a promising potential over the single CDC operation. However, to maximize the benefits of this concept, it is necessary to develop a dedicated optimization work for fitting better the $\mathrm{RCCl}$ concept into the global dual-mode engine map. This procedure must take into account some additional factors than those considered for achieving the widest possible isolated $\mathrm{RCCl}$ operation. In this sense, aside from modifications in engine settings and fuel properties to tailor the GIE in the most appropriate zones of the engine map, the different tradeoffs between the urea necessity, exhaust diesel consumption and $\mathrm{RCCl}$ operation coverage should be studied in detail. This means that the emissions restrictions imposed to $\mathrm{RCCl}$ could be relieved looking for optimizing the engine settings and maximize the GIE bearing in mind the future application of the engine. Another important factor to be considered for broaden the $\mathrm{RCCl}$ operation coverage is the compression ratio of the engine, which has shown a clear effect on the maximum load achievable.

\section{Acknowledgments}

The authors acknowledge VOLVO Group Trucks Technology for supporting this research. The author J. Monsalve-Serrano thanks the Universitat Politècnica de València for his predoctoral contract (FPI-S2-2015-1531), which is included within the framework of Programa de Apoyo para la Investigación y Desarrollo (PAID). Additionally, the authors also wish to thank Gabriel Alcantarilla from CMT - Motores Térmicos for his technical work in adapting the test cell.

\section{References}

[1] Mingfa Y, Zhaolei Z, Haifeng L. Progress and recent trends in homogeneous charge compression ignition $(\mathrm{HCCl})$ engines. Progress in Energy and Combustion Science 35 (5) (October 2009) 398-437.

[2] Shen M., Tuner M., Johansson B., Cannella, W. Effects of EGR and Intake Pressure on PPC of Conventional Diesel, Gasoline and Ethanol in a Heavy Duty Diesel Engine. SAE Technical Paper 2013-01-2702, 2013, doi:10.4271/2013-01-2702.

[3] Singh A P, Agarwal A K. Combustion characteristics of diesel $\mathrm{HCCl}$ engine: an experimental investigation using external mixture formation technique. Appl Energy 2012. Volume 99, November 2012, Pages 116-125.

[4] Kalghatgi G, Risberg P, Angstrom $H$. Advantages of fuels with high resistance to autoignition in late-injection, low-temperature, compression ignition combustion. SAE Trans., 2006, 115(4), 623-634.

[5] Liu H, Yao M, Zhang B, Zheng Z. Effects of inlet pressure and octane numbers on combustion and emissions of a homogeneous charge compression ignition $(\mathrm{HCCl})$ engine. Energy and Fuels, 2008, 22(4), 2207-2215.

[6] Benajes J, García A, Domenech V, Durrett R. An investigation of partially premixed compression ignition combustion using gasoline and spark assistance. Applied Thermal Engineering, Volume 52, Issue 2, 15 April 2013, Pages 468-477. 
[7] Benajes J, García A, Tormos B, Monsalve-Serrano J. Impact of Spark Assistance and Multiple Injections on Gasoline PPC Light Load. SAE Int. J. Engines 7(4):2014, doi:10.4271/2014-01-2669.

[8] Benajes J, Molina S, García A, Monsalve-Serrano J, Durrett R. Performance and engine-out emissions evaluation of the double injection strategy applied to the gasoline partially premixed compression ignition spark assisted combustion concept. Applied Energy, Volume 134, December 2014, Pages 90-101.

[9] Benajes J, Molina S, García A, Monsalve-Serrano J, Durrett R. Conceptual model description of the double injection strategy applied to the gasoline partially premixed compression ignition combustion concept with spark assistance. Applied Energy, Volume 129, September 2014, Pages 1-9.

[10] Bessonette P W, Schleyer C H, Duffy K P, Hardy W L, Liechty M P. Effects of fuel property changes on heavy-duty HCCl combustion. SAE paper 2007-01-0191, 2007.

[11] Inagaki K, Fuyuto T, Nishikawa K, Nakakita K, Sakata I. Dual-fuel PCl combustion controlled by in-cylinder stratification of ignitability. SAE technical paper 2006-010028; 2006.

[12] Kokjohn S, Hanson R, Splitter D, Reitz, R. Experiments and Modeling of DualFuel $\mathrm{HCCl}$ and $\mathrm{PCCl}$ Combustion Using In-Cylinder Fuel Blending. SAE Int. J. Engines 2(2):24-39, 2010, doi:10.4271/2009-01-2647.

[13] Hanson RM, Kokjohn SL, Splitter DA, Reitz RD. An experimental investigation of fuel reactivity controlled $\mathrm{PCCl}$ combustion in a heavy-duty engine. SAE technical paper 2010-01-0864; 2010.

[14] Splitter D A, Wissink M L, Hendricks T L, Ghandhi J B, Reitz R D. Comparison of $\mathrm{RCCl}, \mathrm{HCCl}$, and CDC Operation from Low to Full Load, THIESEL 2012 Conference on Thermo- and Fluid Dynamic Processes in Direct Injection Engines, 2012.

[15] Li Y., Jia M., Chang Y., Fan W., Xie M., Wang T. Evaluation of the necessity of exhaust gas recirculation employment for a methanol/diesel reactivity controlled compression ignition engine operated at medium loads. Energy Conversion and Management, Volume 101, 1 September 2015, Pages 40-51.

[16] Leermakers C, Van den Berge B, Luijten C, Somers L, et al. Gasoline-Diesel Dual Fuel: Effect of Injection Timing and Fuel Balance. SAE Technical Paper 2011-012437, 2011, doi:10.4271/2011-01-2437.

[17] Li J., Yang W., An H., Zhou D., Yu W., Wang J., Li L. Numerical investigation on the effect of reactivity gradient in an $\mathrm{RCCl}$ engine fueled with gasoline and diesel. Energy Conversion and Management, Volume 92, 1 March 2015, Pages 342-352.

[18] Zhou D., Yang W., An H., Li J., Shu C. A numerical study on RCCl engine fueled by biodiesel/methanol. Energy Conversion and Management, Volume 89, 1 January 2015, Pages 798-807.

[19] Kokjohn S L, Hanson R M, Splitter D A, Reitz R D. Fuel reactivity controlled compression ignition (RCCl): a pathway to controlled high-efficiency clean combustion, International Journal of Engine Research, 2011. Volume 12, June 2011, Pages 209-226. 
[20] Desantes JM, Benajes J, García A, Monsalve-Serrano J. The Role of the InCylinder Gas Temperature and Oxygen Concentration over Low Load RCCl Combustion Efficiency. Energy, Volume 78, December 2014, Pages 854-868.

[21] Splitter D A, Kokjohn S L, Wissink M L, Reitz R. Effect of compression ratio and piston geometry on RCCI load limits and efficiency. SAE technical paper 2012-010383; 2012. http://dx.doi.org/10.4271/2012-01-0383.

[22] Dempsey A, Walker N, Reitz R. Effect of Piston Bowl Geometry on Dual Fuel Reactivity Controlled Compression Ignition (RCCI) in a Light-Duty Engine Operated with Gasoline/Diesel and Methanol/Diesel. SAE Int. J. Engines 6(1):78-100, 2013, doi:10.4271/2013-01-0264.

[23] Li J., Yang W., Zhou D. Modeling study on the effect of piston bowl geometries in a gasoline/biodiesel fueled $\mathrm{RCCl}$ engine at high speed. Energy Conversion and Management, Volume 112, March 2016, Pages 359-368.

[24] Benajes J, García A, Pastor JM, Monsalve-Serrano J. Effects of piston bowl geometry on Reactivity Controlled Compression Ignition heat transfer and combustion losses at different engine loads. Energy, Volume 98, March 2016, Pages 64-77.

[25] Benajes J, Pastor JV, García A, Monsalve-Serrano J. An experimental investigation on the Influence of piston bowl geometry on $\mathrm{RCCl}$ performance and emissions in a heavy-duty engine. Energy Conversion and Management, Volume 103, October 2015, Pages 1019-1030.

[26] Benajes J, Pastor JV, García A, Monsalve-Serrano J. The potential of RCCl concept to meet EURO VI NOx limitation and ultra-low soot emissions in a heavyduty engine over the whole engine map. Fuel, Volume 159, November 2015, Pages 952-961.

[27] Directive 2009/28/EC of the European parliament and of the council of 23 April 2009 on the promotion of the use of energy from renewable sources. http://eur-lex.europa.eu.

[28] http://www.volvotrucks.com/trucks/uk-market/en-gb/trucks/volvo-fl/productfeatures/Pages/d5k-and-d8k-engines.aspx

[29] Yu S, Zheng M. Ethanol-diesel premixed charge compression ignition to achieve clean combustion under high loads. Proceedings of the Institution of Mechanical Engineers, Part D: Journal of Automobile Engineering, 2015. doi: 10.1177/0954407015589870.

[30] Klos D, Janecek D, Kokjohn S. Investigation of the Combustion Instability-NOx Tradeoff in a Dual Fuel Reactivity Controlled Compression Ignition (RCCI) Engine. SAE Int. J. Engines 8(2):2015, doi:10.4271/2015-01-0841.

[31] Agarwal A., Pandey A., Gupta A., Aggarwal S., Kushari A. Novel Combustion Concepts for Sustainable Energy Development. Springer. ISBN 978-81-322-2211-8.

[32] Benajes J, Molina S, García A, Monsalve-Serrano J. Effects of low reactivity fuel characteristics and blending ratio on low load $\mathrm{RCCl}$ (reactivity controlled 
compression ignition) performance and emissions in a heavy-duty diesel engine. Energy, Volume 90, October 2015, Pages 1261-1271.

[33] Benajes J, Molina S, García A, Monsalve-Serrano J. Effects of Direct injection timing and Blending Ratio on RCCl combustion with different Low Reactivity Fuels. Energy Conversion and Management, Volume 99, July 2015, Pages 193-209.

[34] Payri, R., Gimeno, J., Novella R., Bracho G. On the rate of injection modeling applied to direct injection compression ignition engines. International Journal of Engine Research, 2016, doi: 10.1177/1468087416636281.

[35] Bosch W. The fuel rate indicator: a new instrument for display of the characteristic of individual injection. SAE Paper 660749; 1966.

[36] Payri F, Olmeda P, Martín J, García A. A complete OD thermodynamic predictive model for direct injection diesel engines. Applied Energy, Volume 88, Issue 12, December 2011, Pages 4632-4641.

[37] Payri F, Olmeda P, Martin J, Carreño R. A New Tool to Perform Global Energy Balances in DI Diesel Engines. SAE Int. J. Engines 7(1):2014, doi:10.4271/2014-010665.

[38] Lapuerta M., Armas O. y Hernandez J. J. "Diagnosis of DI Diesel combustion from in-cylinder pressure signal by estimation of mean thermodynamic properties of the gas". Applied Thermal Engineering, Vol. 19 no 5, pp. 513-529, 1999.

[39] Woschni G. "A universally applicable equation for the instantaneous heat transfer coefficient in the internal combustion engines". SAE Paper 670931, 1967.

[40] Payri F., Margot X., Gil A. y Martin J. "Computational study of heat transfer to the walls of a DI diesel engine". SAE Paper 2005-01-0210, 2005.

[41] Torregrosa A. J., Olmeda P., Degraeuwe B. y Reyes M. "A concise wall temperature model for DI Diesel engines". Applied Thermal Engineering, Vol. 26 no 11-12, pp. 1320-1327, 2006.

[42] Prikhodko V, Curran S, Parks J, Wagner R. Effectiveness of Diesel Oxidation Catalyst in Reducing $\mathrm{HC}$ and $\mathrm{CO}$ Emissions from Reactivity Controlled Compression Ignition. SAE Int. J. Fuels Lubr. 6(2):329-335, 2013, doi:10.4271/2013-01-0515.

[43] Splitter D, Wissink M, DelVescovo D and Reitz R. Improving the Understanding of Intake and Charge Effects for Increasing RCCI Engine Efficiency. SAE Int. J. Engines 7(2):2014, doi:10.4271/2014-01-1325.

[44] Johnson T. Diesel Emissions in Review. SAE Int. J. Engines, 4(1):143-157, 2011, doi:10.4271/2011-01-0304.

[45] Singh N, Rutland C, Foster D, Narayanaswamy K, Yongsheng H. Investigation into Different DPF Regeneration Strategies Based on Fuel Economy Using Integrated System Simulation. SAE Technical Paper 2009-01-1275, 2009, doi:10.4271/2009-01-1275.

[46] Gong J, Rutland C. Pulsed Regeneration for DPF Aftertreatment Devices. SAE Technical Paper 2011-24-0182, 2011, doi:10.4271/2011-24-0182. 
[47] Prikhodko V, Parks J. Implications of Low Particulate Matter Emissions on System Fuel Efficiency for High Efficiency Clean Combustion. SAE Technical Paper 2009-01-2709, 2009, doi:10.4271/2009-01-2709.

\section{Abbreviations}

ASTM: American Society of Testing and Materials

ATDC: After Top Dead Center

CAD: Crank Angle Degree

CA10: Crank angle at $10 \%$ mass fraction burned

CA50: Crank angle at 50\% mass fraction burned

CDC: Conventional Diesel Combustion

CO: Carbon Monoxide

CR: Compression Ratio

DI: Direct Injection

DPF: Diesel Particulate Filter

ECU: Electronic Control Unit

EGR: Exhaust Gas Recirculation

EOI: End of Injection

EU: European Union

EVO: Exhaust Valve Open

FSN: Filter Smoke Number

HC: Hydro Carbons

$\mathrm{HCCl}$ : Homogeneous Charge Compression Ignition

MPRR: Maximum Pressure Rise Rate

IMEP: Indicated Mean Effective Pressure

ISFC: Indicated Specific Fuel Consumption

IVC: Intake Valve Close

IVO: Intake Valve Open

LNT: Lean NOx Trap

LTC: Low Temperature Combustion

MCE: Multi Cylinder Engine

OEM: Original Equipment Manufacturer

ON: Octane Number 
PFI: Port Fuel Injection

PPC: Partially Premixed Charge

PRR: Pressure Rise Rate

RCCI: Reactivity Controlled Compression Ignition

RED: Renewable Energy Directive

RoHR: Rate of Heat Release

RI: Ringing Intensity

SOC: Start of Combustion

SOI: Start of Injection

SCE: Single Cylinder Engine

SCR: Selective Catalytic Reduction 